\title{
Standard versus prosocial online support groups for distressed breast cancer survivors: a randomized controlled trial
}

\author{
Stephen J Lepore ${ }^{1 *}$, Joanne S Buzaglo², Morton A Lieberman ${ }^{3}$ Mitch Golant ${ }^{2}$ and Adam Davey ${ }^{1}$
}

\begin{abstract}
Background: The Internet can increase access to psychosocial care for breast cancer survivors through online support groups. This study will test a novel prosocial online group that emphasizes both opportunities for getting and giving help. Based on the helper therapy principle, it is hypothesized that the addition of structured helping opportunities and coaching on how to help others online will increase the psychological benefits of a standard online group.

Methods/Design: A two-armed randomized controlled trial with pretest and posttest. Non-metastatic breast cancer survivors with elevated psychological distress will be randomized to either a standard facilitated online group or to a prosocial facilitated online group, which combines online exchanges of support with structured helping opportunities (blogging, breast cancer outreach) and coaching on how best to give support to others. Validated and reliable measures will be administered to women approximately one month before and after the interventions. Self-esteem, positive affect, and sense of belonging will be tested as potential mediators of the primary outcomes of depressive/anxious symptoms and sense of purpose in life.

Discussion: This study will test an innovative approach to maximizing the psychological benefits of cancer online support groups. The theory-based prosocial online support group intervention model is sustainable, because it can be implemented by private non-profit or other organizations, such as cancer centers, which mostly offer face-toface support groups with limited patient reach.
\end{abstract}

Trial Registration: ClinicalTrials.gov: NCT01396174

\section{Background}

Ongoing and timely access to relevant information and social support can improve psychological outcomes in breast cancer patients [1], but such access is far from universal [2]. The Internet can increase access to psychosocial care through online support groups (OSGs), yet the few randomized trials of cancer OSGs have yielded mixed results [3-6]. Thus, there is a need to develop innovative approaches to maximizing the psychological benefits of OSGs. An obvious benefit of a support group is access to information and emotional support from similar others. Less obvious are the benefits accrued from providing help to others. According to

\footnotetext{
* Correspondence: slepore@temple.edu

${ }^{1}$ Temple University, Department of Public Health, 1301 Cecil B. Moore Ave.,

$9^{\text {th }}$ Floor Ritter Annex, Philadelphia, PA, 19122, USA Full list of author information is available at the end of the article
}

the "helper therapy principle," [7] helping benefits the helper, possibly enhancing psychological and physical health outcomes [8-11]. Based on this theory and prior research, we hypothesized that OSGs that maximize opportunities for providing help to others would be highly efficacious at reducing distress symptoms.

Depression and anxiety symptoms are highly prevalent among breast cancer survivors [12] and often undertreated [13]. A systematic review found high rates of probable depression in breast cancer patients $(10 \%$ to $25 \%$ ) [13]. In a rare 5 -year cohort study, nearly $50 \%$ of women with early breast cancer had depression, anxiety, or both one year after diagnosis, $25 \%$ in the second, third, and fourth years, and 15\% in the fifth year [14]. Controlling distress is important in its own right, but clinically it may be important to address psychological distress in breast cancer patients in the early years after
C Biomed Central 
treatment because it can be detrimental to quality of life, treatment adherence, cancer surveillance, health behaviors (e.g., exercise, diet), self-care (e.g., managing lymphedema), and overall health outcomes including risk for recurrence, and decreased immune function [12,15-19]. Breast cancer may bring about distress, in part, through its adverse effects on self-esteem [20], sense of social belonging [21], and sense of purpose $[22,23]$. Amount of helping others has been shown to be positively related to all of these outcomes and inversely related to depression $[24,25]$. Thus, an intervention promoting prosocial behavior might reduce distress in breast cancer survivors directly and indirectly through these psychological correlates of distress.

Dozens of interventions have been designed to reduce distress in cancer survivors, but the evidence on their efficacy and acceptability is weak [26,27]. Moreover, many interventions that require in-person contact are expensive and do not reach patients who might be constrained by time, money, mobility, or location. OSGs are a fairly low cost alternative to in-person interventions and overcome many of the obstacles of in-person interventions. Breast cancer survivors often use OSGs [28], so this population should be receptive to an OSG intervention.

To date, the evidence on the efficacy of cancer OSGs is limited. Winzelberg et al. [3] randomized 72 breast survivors to a professionally facilitated OSG or a waitlist control group. Compared with the controls, OSG participants had significantly greater reductions in depressive symptoms (effect size $=0.54$ ) from baseline to follow-up. Fifty-three percent of OSG participants who were depressed at baseline were below the clinical cut-point at follow-up, compared with only $29 \%$ improvement in the control group. Owen et al. [6] randomized 62 breast cancer survivors to an Internet-based coping-skills training group (with access to a non-facilitated peer discussion board) or to a wail-list control group and found no intervention effects on quality of life. Similarly, Salzer et al. [4] randomized 78 breast cancer survivors to a non-facilitated OSG or to an Internetbased education control group and found no intervention effects on distress or quality of life. And, finally, Gustafson et al. [5] randomized 295 breast cancer survivors to a non-facilitated OSG or to a control group and found no intervention effects on quality of life. Given this mixed evidence, we cannot draw firm conclusions on the efficacy of cancer OSGs. The field must identify ways to maximize the psychological benefits derived from OSGs if they are to be recommended.

The current study will develop and evaluate a novel OSG intervention that theoretically should boost the benefits observed in standard facilitated OSGs [3,29]. Most social support research focuses on the health benefits of receiving social support [30], but there is evidence that providing social support also confers benefits [11,31-33]. Some research even suggests that providing support is more beneficial than receiving support $[10,31]$. In general, engagement in prosocial actions (e.g., helping, advising) appears to enhance health and quality of life outcomes [33,34]. However, the bulk of empirical evidence on the benefits of helping comes from observational studies with non-clinical populations. Studies using controlled experimental [35] or longitudinal observational designs [36] are rare. The current trial is the first to evaluate the psychological benefits of increasing helping behaviors among distressed cancer survivors in the context of an online supportive intervention.

The trial also aims to identify potential mechanisms underlying the psychological benefits of helping. Based on the literature and Midlarsky's [33] conceptual framework, we developed the model in Figure 1. The model identifies several potential mediating variables that have been linked both to helping behavior and to psychological distress. Helping has been positively correlated with self-esteem [37] and positive affect [38], which, in turn, have been negatively correlated with psychological distress $[39,40]$. The role of positive affect is of particular interest given the evidence that positive emotions do not just signal optimal psychological functioning, but they can produce it [41]. Positive emotions also can facilitate coping with stress [42]. Helping others also can increase a sense of belonging, or mattering to others [43], which, in turn, has been linked to lower levels of depression and anxiety [44,45]. Further, we anticipate that sense of belonging will be indirectly related to psychological distress through its effects on sense of purpose. The formation of interpersonal attachments has been called a fundamental human need [46]. Belonging to a group and having a role in that group can have a powerful influence on one's sense of purpose [47]. Cancer survivors often report a diminished sense of purpose and meaning in life [22,48]. In turn, a lack of purpose is associated with psychological symptoms of depression and anxiety [49]. If establishing meaningful connections with others can promote or restore a sense of purpose, it could also reduce distress [50].

\section{Objectives and Hypotheses}

The major objective of the "Life Beyond Cancer" trial is to test the efficacy, acceptability, and feasibility of a novel OSG for distressed breast cancer survivors that provides structured helping opportunities and coaching on how best to give support to others. The trial targets distressed breast cancer survivors because they will likely benefit more than non-distressed patients from psychosocial interventions [51]. The study will explore whether the enhanced OSG increases the exchange of 


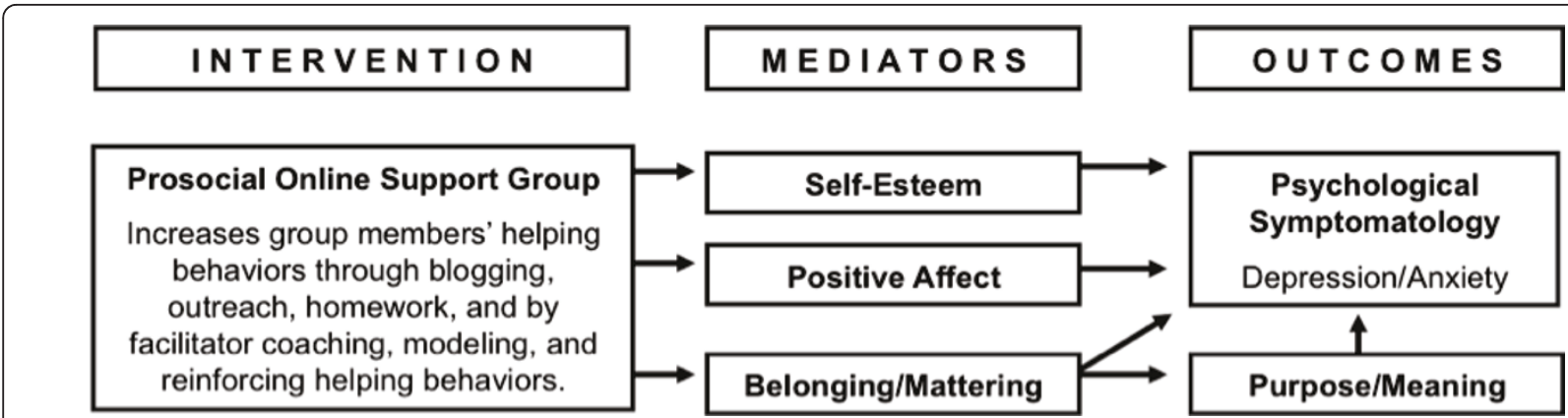

Figure 1 Conceptual model for Life Beyond Cancer trial.

helping behaviors among distressed breast cancer survivors and, consequently, reduces their psychological distress symptoms and increases their sense of purpose relative to their counterparts in a standard OSG. Secondarily, we will evaluate potential psychological mediators of the enhanced, prosocial OSG, and evaluate the acceptability and feasibility of implementing the prosocial OSG among distressed breast cancer survivors.

Hypothesis 1: Relative to women in the standard OSG (S-OSG) condition, women in the prosocial OSG (POSG) condition will have a lower mean level of depression/anxiety symptoms at posttest.

Hypothesis 2: Relative to women in the S-OSG condition, women in the P-OSG condition will have a significantly greater mean level of sense of purpose in life, self-esteem, positive affect, and sense of belonging at posttest.

Hypothesis 3: Positive increases (posttest-pretest) in mean level of self-esteem, positive affect, and sense of belonging will partially mediate the effects of the P-OSG intervention on mean level of depression/anxiety symptoms and sense of purpose at posttest.

Hypothesis 4: Positive increases (posttest-pretest) in mean level of sense of purpose will partially mediate the effects of the P-OSG intervention on mean level of depression/anxiety symptoms at posttest.

Hypothesis 5: Given the equal level of attention across conditions, we hypothesize that there will be no significant between group differences in retention (percent completing study) and mean level of satisfaction with the intervention.

\section{Methods/Design}

A two-group randomized controlled trial design with pretest and posttest measures will be used to address the study aims. Distressed breast cancer survivors will be randomized equally to one of two groups: (a) P-OSG, a facilitated OSG with structured helping opportunities and coaching on how to recognize and be responsive to others needs for help or (b) S-OSG, a comparison standard facilitated OSG. Data will be collected approximately one month before and after the intervention. The study design is guided by the CONSORT criteria [52]. The study is in compliance with the Helsinki Declaration and has received approval from the Temple University Institutional Review Board (protocol number 13705).

\section{Participants}

Eligibility inclusion criteria are: diagnosed with stage I or II breast cancer within the preceding 36 months; age 21 to 65 years (the age cap minimizes sampling women with cognitive or physical impairments that could limit participation and maximizes sampling women with computer experience), access to and ability to use a computer and the Internet, able to understand the informed consent form, fluent in spoken English, and meet the screening criteria for psychological distress. Women will qualify as distressed if they fall above the "non-case" cut-point $(\geq 8)$ on either the depression or anxiety subscale of the Hospital Anxiety and Depression Scales (HADS [53]). This approach will generate a sample with a range of subclinical and clinical levels of distress symptoms [54]. We will not exclude women who previously have participated in an OSG or received other psychosocial treatments. Instead we will measure these variables and include them as covariates in analyses if necessary.

\section{Procedures}

The sampling frame will be generated in conjunction with a State Cancer Tumor Registry and will target women meeting the age and diagnostic criteria. Advance letters will be sent to potential participants. Respondents will be screened for eligibility using standardized measures administered over the phone. Eligible participants will be consented. Non-eligible participants will be sent a resource list.

Trained research assistants will collect data via structured telephone interviews. A random subset of 
interviews will be monitored and reviewed for quality control. Interviewers will be blind to participants' intervention condition. Within one month following end of treatment, participants will be re-interviewed to collect follow-up data. Again, a random subset of interviews will be reviewed for quality control and interviewers will remain blind to participants' condition.

Because age is related to level of Internet use [55] and to level of psychological distress in breast cancer samples [56], age-stratified block randomization (< 51 vs. 51 + years) will be used to assign women to condition and ensure that age is balanced across treatment arms. The project statistician $(\mathrm{AD})$ generated the random sequence using a random numbers generator within STATA (STATACorp, LP, College Station, TX, 2011). Following baseline data collection, the project director, who will be blind to participants' baseline data, will determine participants' assignment using the randomization schedule and inform the group facilitator via email. The facilitator will contact the participant with further instructions on group participation.

Facilitators will be graduate-level, trained health professionals. Trained researchers will use treatment fidelity checklists to evaluate facilitators' adherence to study protocols. Co-investigators will conduct supervision sessions with facilitators to review treatment fidelity and to address any problems.

\section{Measures}

All major study measures have established reliability and validity. The primary outcome measure will be the HADS, which has been used extensively and validated with breast cancer and other cancer patient populations [57]. The HADS can be used to generate continuous measures of symptoms of depression and anxiety and also provides clinical cut-offs. The secondary outcome, sense of purpose, will be measured using the validated and reliable Meaning in Life Questionnaire [58]. Validated and reliable measures also will be used to assess the three mediators: self-esteem with Rosenberg's SelfEsteem scale [59], positive affect with the Positive Affect Scale [60], and sense of belonging (i.e., mattering to others) with the General Mattering Scale [61].

Measures of potential covariates include background variables (e.g., age, race, treatments) and other potential confounding variables [e.g., Social Provisions Scale [62] to measure social support received by social network members, Comorbidity Questionnaire [63] to measure comorbid health conditions, and questions about receipt of formal (e.g., counseling, medication) and informal (e. g., support groups) psychosocial interventions including participation in online support groups unrelated to the study]. Level of "satisfaction" with and perceived "helpfulness" of different intervention elements (e.g., support received, opportunities to help others, interactions with facilitators) will be assessed using 5-point Likert-type scales $(1=$ very unsatisfied to $5=$ very satisfied $)$.

Finally, as a manipulation check, we will assess if the P-OSG intervention increased helping behaviors relative to the S-OSG. Research assistants will code instances of online support provisions using Bambina's Support OnLine (SOL) coding scheme [64]. SOL can be used to reliably code major categories of informational and emotional support provision. Coders will be blind to intervention condition. As part of the process assessment, POSG participants also will answer questions about perceived barriers or concerns with the "outreach" and "blogging" activities (see below).

\section{Interventions}

\section{Standard online support group intervention}

The S-OSG comparison condition is based on an empirically validated facilitated breast cancer OSG $[3,29]$. The intervention is manualized and interventionists will receive regular monitoring and supervision by $\mathrm{PhD}$-level clinical psychologists with experience running cancer OSGs. The OSGs are modeled after face-to-face support groups [e.g., $[65,66]$, such as those conducted in community settings throughout North America (i.e., Gilda's Club, Cancer Support Community). While the proposed OSG is distinct in that specific topics are introduced at each session, several components remain consistent with the face-to-face model; including all sessions are professionally led and participants are considered the experts in their own experience. The groups will meet online weekly for approximately 1.5 hours and participants will be able to email and chat. Each week the facilitator will introduce a new topic and encourage participants to share their relevant experiences, concerns, and problems. The facilitator will not encourage people to help others, but instead focus on promoting self-expression (e.g., "Tell us more about the pain in your arm.").

The weekly topics, which were drawn from research on breast cancer survivorship [e.g., [67-69], include: (1) symptoms of pain, fatigue and lymphedema; (2) selfesteem and body image concerns; (3) problems in physical and recreational activities; (4) problems in intimacy, sexual interest and function; (5) coping with depression, anxiety, and fears of recurrence; and (6) challenges to staying healthy (diet, exercise, surveillance). In addition, as a control for the "helping blog" activity in the P-OSG condition (see below), participants in the S-OSG will be asked to select one of the six weekly topics that they wish to write about as a way to organize some of their thoughts and feelings. This type of writing is similar to expressive writing, which no study to date has found to be effective in reducing psychological distress in breast 
cancer survivors [70], so it serves as an effective attention control for the "helping blog" activity. The writing will be private and not shared with anyone, including the research team.

\section{Prosocial online support group intervention}

The P-OSG intervention includes elements of the SOSG, but with critical modifications and key additions. First, participants will receive a tip sheet that describes how to recognize others' needs for different kinds of support and how to be helpful in an online environment. Second, the facilitator will post reminders at the beginning of each session on the importance of responding to one another's needs for help. Third, participants will be asked to commit to a goal of offering informational or emotional support to group members each week during the live synchronous sessions or later using the discussion board, email or chat. Fourth, prior to each week's meeting, participants will receive an email describing the topical problem to be discussed (e. g., pain, fatigue, and lymphedema). Their "homework" is to prepare 1-2 sentences on how their experiences with the problem might help others to cope with the problem. If they have not had the problem, they will be asked to write 1-2 sentences on how their approach to coping with other life problems might be useful to group members coping with the particular problem of the week. Fifth, the facilitator will encourage helping by highlighting direct and indirect requests for support by group members, will praise those who offer help (e.g., "Nice suggestion, Margie."), and will encourage additional help (e.g., "Has anyone else found a good way to cope with the problem Joan mentioned?").

Members of the P-OSG also will be asked to select one of the six weekly topics to prepare a blog about the topic to share with the group. The goal will be to write about their experience as a way of helping other breast cancer survivors who have gone through a similar experience. The writing instructions will emphasize that participants should not worry about grammar or spelling and that if they wish the research staff can help to edit their writing for grammar or spelling before posting. Participants will be asked to blog about any effective ways they have developed to cope with a cancer-related problem. The exercise will emphasize that people often have experiential knowledge that is valuable to others, but can only be accessed if there is sharing. Bloggers will be told that the exercise is designed to help other patients to understand the different consequences of breast cancer and its treatment, as well as how they might best manage or address these consequences. Instructions also will explain that the bloggers do not necessarily have to provide answers or solutions to the problems they write about, they simply need to share their experience. Reading others similar experiences can help to normalize the experience or make readers feel less alone. We recognize that some participants might be resistant to sharing their writings with others, either because they do not feel it will be valuable or they feel it is too personal. We will offer individuals the opportunity to have their blog posted anonymously, or only post select information, or for us to paraphrase what they have written in a list of comments comprised of input from multiple blogs. All blogs will be fact checked by research staff to avoid posting misinformation.

Finally, in addition to promoting helping within the group, the P-OSG will promote helping outside of the group through an outreach activity called the "Breast Cancer Awareness Ambassadors" program. Women in the P-OSG group will be asked to increase breast cancer awareness by sharing a "Breast Cancer and You" fact sheet and "Mammograms Save Lives" e-Cards, both developed by the Centers for Disease Control and Prevention, with women in their social network who are 40 + years old.

\section{Analytic Plan}

Descriptive statistics will be generated for the total sample and the treatment groups for each time point. Distributional properties will be analyzed to determine if variance stabilizing or normalizing transformations should be applied. Outliers will be assessed and checked for accuracy. Non-response and attrition must be addressed in longitudinal research [71]. Therefore, full information maximum likelihood (FIML) and multiple imputations (MI) will be used to correct for missing data [71]. Variables associated with missing data mechanisms will be included as covariates in models or used to create multiple imputations as appropriate. Both FIML and MI are implemented in a variety of software packages including LISREL, AMOS, and MPlus, each of which can accommodate all statistical models (ANCOVA, OLS and logistic regression, mediation models, etc.) that will be estimated in this project.

Hypotheses 1 and 2: Post-test differences between POSG and S-OSG in primary and secondary outcomes will be tested using ANCOVA, with intervention group as the predictor and appropriate pre-test scores as covariates. Intent-to-treat analyses will be used. Variance associated with cohort membership will be estimated via intraclass correlation coefficients. If necessary cohort can be entered into the ANCOVA models as a random effect or fixed-effects analyses can be performed if there is evidence for unobserved heterogeneity. Group-level analyses can be performed on aggregate data if necessary.

Hypotheses 3 and 4: Mediation will be tested in a series of ANCOVA models using standard statistical software or structural equation modeling software. 
Hypothesis tests will be based on bootstrapped standard errors [72].

Hypothesis 5: Acceptability will be assessed by recruitment and retention rates, reasons for refusal/dropout, and level of participants' ratings of satisfaction and helpfulness of different intervention elements. Fisher's exact test will be used to evaluate differences between conditions for categorical outcomes; t-tests or non-parametric equivalents can be performed to compare ordinal or continuous outcomes.

The feasibility of manipulating online helping behavior will be assessed by comparing mean levels of observed helping behaviors (using SOL data) enacted by participants in the P-OSG versus S-OSG and participants' willingness and ability to generate a "helping blog" and engage in "outreach" activities in the P-OSG condition. Additional analyses will be conducted to confirm that treatment fidelity was equivalent across conditions and to explore dose-response relations by examining whether level of participation (e.g., attendance, number of posts, amount of help provided to others) moderates intervention effects.

Because this is a preliminary study of the effect of the novel P-OSG intervention, we are interested in estimating effect sizes of the P-OSG intervention group. More specifically, we are interested in gaining an estimate of the true treatment effect size (which is independent of sample size) and to establish a plausible confidence interval around this effect size. Thus, we present information regarding the aim of accuracy in parameter estimation (AIPE) [73] as well as information relevant to the aim of null hypothesis significance testing.

AIPE identifies a range (half-width, $w$ ) within which an effect size can be bracketed with a specified probability, independent of the magnitude of the observed effect size. It is easiest to interpret in the metric of standardized regression coefficients, i.e., $\beta \pm w$. For these analyses, AIPE will depend on (a) the number of predictors, (b) variance in predictor of interest accounted for by other predictors, $R_{x x}^{2}$, and (c) overall variance predicted in outcome, $R_{y x}^{2}$. Our models will have between 2 (pretest \& treatment) and 10 predictors (i.e., adding 3 mediators and possibly 5 cohort identifier dummy variables). We estimated half-widths assuming: model $R_{y x}^{2}$ was either high (.5) or low (.1) and $R_{x x}^{2}$ was zero (treatment), low (.1) or high (.5). With $80 \%$ probability for $\mathrm{N}=180$ (90 per experimental condition), we expect to be able to bracket effect sizes for treatment effects within \pm .11 to \pm .15 depending on model $\mathrm{R}^{2}$. Effect sizes for mediators will be estimated with somewhat less precision but within \pm .12 to \pm .22
Power to identify post-test differences between P-OSG and S-OSG controlling for pre-test values and group membership depends on the correlation between pretest and post-test scores. Minimum detectable effect size $(\hat{d})$ with power $=.8$ and $\alpha=.05$, is well approximated $\left(\mathrm{R}^{2}>\right.$.99) for specific pre-post correlations $\left(\mathrm{r}_{01}\right)$ by the formula: $\hat{d}=0.41+0.08 r_{01}-0.36 r_{01}^{2}$ and ranges from $.19\left(\mathrm{r}_{01}=.9\right)$ to $.42\left(\mathrm{r}_{01}=0\right)$.

\section{Discussion}

In terms of clinical practice, we believe that the current lack of conclusive evidence on the efficacy of OSGs has stymied the broader implementation and dissemination of facilitated OSGs. The majority of National Cancer Institute-designated cancer centers in the United States, as well as community-based hospitals and cancer centers, primarily offer face-to-face supportive care, which is costly and has limited patient reach. If successful, results of the proposed trial could stimulate broader implementation of facilitated OSGs and offer an innovative approach to implementing OSGs that emphasizes prosocial behavior within the group and outside the group. Specifically, the proposed prosocial OSG model offers an alternative to the dominant self-help OSG, which lacks facilitation and emphasizes emotional expression over mutual exchange of help. Importantly, the prosocial OSG provides a model for practice that can be easily adopted by organizations that offer psychosocial care to cancer survivors.

\section{List of abbreviations}

The following abbreviations were used: AIPE: accuracy in parameter estimation; ANCOVA: Analysis of covariance; FIML: full information maximum likelihood; MI: multiple imputation; OLS: ordinary least squares; OSG: Online support group; P-OSG: prosocial online support group; S-OSG: standard online support group.

\section{Acknowledgements}

National Institutes of Health grant R21CA15877 funded this trial and supported all investigators.

\section{Author details \\ ${ }^{1}$ Temple University, Department of Public Health, 1301 Cecil B. Moore Ave., $9^{\text {th }}$ Floor Ritter Annex, Philadelphia, PA, 19122, USA. ${ }^{2}$ Cancer Support Community, Research \& Training Institute, 4100 Chamounix Drive, Philadelphia, PA, 19131, USA. ${ }^{3}$ University of California San Francisco, 1104 Western Ave, Mill Valley, Ca. 94941, USA.}

\section{Authors' contributions}

SJL, JB, ML, MG developed the study concept and aims. AD assisted with the analytic plan. SJ drafted the manuscript. SL and JB will implement the protocol. SL will oversee enrollment and data collection. JB, ML and MG will oversee facilitator training and monitoring. AD will assist with sampling, randomization procedures and data analysis. All authors contributed to and approved the final manuscript.

\section{Competing interests}

The authors declare that they have no competing interests. 
Received: 16 August 2011 Accepted: 25 August 2011

Published: 25 August 2011

\section{References}

1. Helgeson VS, Cohen S: Social support and adjustment to cancer: reconciling descriptive, correlational, and intervention research. Health Psychol 1996, 15(2):135-148.

2. Peters-Golden $\mathrm{H}$ : Breast cancer: varied perceptions of social support in the illness experience. Soc Sci Med 1982, 16(4):483-491.

3. Winzelberg AJ, Classen C, Alpers GW, Roberts H, Koopman C, Adams RE, Ernst H, Dev P, Taylor CB: Evaluation of an internet support group for women with primary breast cancer. Cancer 2003, 97(5):1164-1173.

4. Salzer MS, Palmer SC, Kaplan K, Brusilovskiy E, Ten Have T, Hampshire M, Metz J, Coyne JC: A randomized, controlled study of Internet peer-topeer interactions among women newly diagnosed with breast cancer. Psychooncology 2009.

5. Gustafson DH, Hawkins R, Pingree S, McTavish F, Arora NK, Mendenhall J, Cella DF, Serlin RC, Apantaku FM, Stewart J, et al: Effect of computer support on younger women with breast cancer. J Gen Intern Med 2001, 16(7):435-445

6. Owen JE, Klapow JC, Roth DL, Shuster JL, Bellis J, Meredith R, Tucker DC Randomized pilot of a self-guided internet coping group for women with early-stage breast cancer. Ann Behav Med 2005, 30(1):54-64.

7. Reissman F: The helper-therapy principle. Social Work 1965, 10:27-32

8. Liang J, Krause NM, Bennett JM: Social exchange and well-being: is giving better than receiving? Psychol Aging 2001, 16(3):511-523.

9. Brown WM, Consedine NS, Magai C: Altruism relates to health in an ethnically diverse sample of older adults. J Gerontol B Psychol Sci Soc Sci 2005, 60(3):P143-152.

10. Roberts L, Salem D, Rappaport J, Toro PA, Luke DA, Seidman E: Giving and receiving help: interpersonal transactions in mutual-help meetings and psychosocial adjustment of members. Am J Community Psychol 1999, 27(6):841-868.

11. Schwartz C, Meisenhelder JB, Ma Y, Reed G: Altruistic social interest behaviors are associated with better mental health. Psychosom Med 2003, 65(5):778-785

12. Reich M, Lesur A, Perdrizet-Chevallier C: Depression, quality of life and breast cancer: a review of the literature. Breast Cancer Res Treat 2008, 110(1):9-17.

13. Fann JR, Thomas-Rich AM, Katon WJ, Cowley D, Pepping M, McGregor BA, Gralow J: Major depression after breast cancer: a review of epidemiology and treatment. Gen Hosp Psychiatry 2008, 30(2):112-126.

14. Burgess C, Cornelius V, Love S, Graham J, Richards M, Ramirez A: Depression and anxiety in women with early breast cancer: five year observational cohort study. BMJ 2005, 330(7493):702.

15. Hong S, Bardwell WA, Natarajan L, Flatt SW, Rock CL, Newman VA, Madlensky L, Mills PJ, Dimsdale JE, Thomson CA, et al: Correlates of physical activity level in breast cancer survivors participating in the Women's Healthy Eating and Living (WHEL) Study. Breast Cancer Res Treat 2007, 101(2):225-232.

16. DiMatteo MR, Lepper HS, Croghan TW: Depression is a risk factor for noncompliance with medical treatment: meta-analysis of the effects of anxiety and depression on patient adherence. Arch Intern Med 2000, 160(14):2101-2107.

17. Honda K, Goodwin RD, Neugut Al: The associations between psychological distress and cancer prevention practices. Cancer Detect Prev 2005, 29(1):25-36

18. Lerman C, Kash K, Stefanek M: Younger women at increased risk for breast cancer: perceived risk, psychological well-being, and surveillance behavior. J Natl Cancer Inst Monogr 1994, 16: 171-176.

19. Giese-Davis J, Collie K, Rancourt KM, Neri E, Kraemer HC, Spiegel D: Decrease in depression symptoms is associated with longer survival in patients with metastatic breast cancer: a secondary analysis. J Clin Oncol 2011, 29(4):413-420

20. Lepore SJ, Glaser DB, Roberts KJ: On the positive relation between received social support and negative affect: a test of the triage and selfesteem threat models in women with breast cancer. Psychooncology 2008, 17(12):1210-1215.

21. Rosedale M: Survivor loneliness of women following breast cancer. Oncol Nurs Forum 2009, 36(2):175-183.
22. Kernan WD, Lepore SJ: Searching for and making meaning after breast cancer: prevalence, patterns, and negative affect. Soc Sci Med 2009, 68(6):1176-1182.

23. White CA: Meaning and its measurement in psychosocial oncology. Psychooncology 2004, 13(7):468-481.

24. Taylor J, Turner J: A longitudinal study of the role and significance of mattering to others for depressive symptoms. Journal of Health and Social Behavior 2001, 42:310-325.

25. Baumeister RF: Meanings of life. NY: Guilford; 1991.

26. Lepore SJ, Coyne JC: Psychological interventions for distress in cancer patients: a review of reviews. Ann Behav Med 2006, 32(2):85-92.

27. Coyne JC, Lepore SJ, Palmer SC: Efficacy of psychosocial interventions in cancer care: evidence is weaker than it first looks. Ann Behav Med 2006, 32(2):104-110.

28. Davison KP, Pennebaker JW, Dickerson SS: Who talks? The social psychology of illness support groups. Am Psychol 2000, 55(2):205-217.

29. Lieberman MA, Golant M, Giese-Davis J, Winzlenberg A, Benjamin H, Humphreys K, Kronenwetter C, Russo S, Spiegel D: Electronic support groups for breast carcinoma: a clinical trial of effectiveness. Cancer 2003, 97(4):920-925.

30. Uchino BN: Social support and physical health: Understanding the health consequences of relationships. New Haven, CT: Yale University Press; 2004

31. Brown SL, Nesse RM, Vinokur AD, Smith DM: Providing social support may be more beneficial than receiving it: results from a prospective study of mortality. Psychol Sci 2003, 14(4):320-327.

32. Post SG: It's good to be good: science says it's so. Research demonstrates that people who help others usually have healthier, happier lives. Health Prog 2009, 90(4):18-25.

33. Midlarsky E: Helping as coping. In Prosocial behavior. Edited by: Clark MS. Newbury Park, CA: Sage; 1991:238-264.

34. Post SG: Altruism and health: Perspectives from empirical research. NY: Oxford; 2007.

35. Eyler J: Linking service and learning - linking students and communities. Journal of Social Issues 2002, 58:517-534.

36. Wink P, Dillon M: Do generative adolescents become health older adults? In Altruism \& Health. Edited by: Post SG. NY: Oxford; 2007:43-55.

37. Schwartz CE, Sendor M: Helping others helps oneself: response shift effects in peer support. Soc Sci Med 1999, 48(11):1563-1575.

38. Midlarsky E, Kahana E: Altruism in later life. Thousand Oaks, CA: Sage; 1994

39. Schroevers MJ, Ranchor AV, Sanderman R: The role of social support and self-esteem in the presence and course of depressive symptoms: a comparison of cancer patients and individuals from the general population. Soc Sci Med 2003, 57(2):375-385.

40. Eton DT, Lepore SJ, Helgeson VS: Early quality of life in patients with localized prostate carcinoma: an examination of treatment-related, demographic, and psychosocial factors. Cancer 2001, 92(6):1451-1459.

41. Fredrickson BL: The broaden-and-build theory of positive emotions. Philos Trans R Soc Lond B Biol Sci 2004, 359(1449):1367-1378.

42. Aspinwall $L G$, Taylor SE: A stitch in time: self-regulation and proactive coping. Psychol Bull 1997, 121(3):417-436.

43. Schwartz CE, Keyl PM, Marcum JP, Bode R: Helping others shows differential benefits on health and well-being of male and female teens. Journal of Happiness Studies 2009, 10:431-448.

44. Hagerty BM, Williams RA, Coyne JC, Early MR: Sense of belonging and indicators of social and psychological functioning. Arch Psychiatr Nurs 1996, 10(4):235-244.

45. Bay E, Hagerty BM, Williams RA, Kirsch N, Gillespie B: Chronic stress, sense of belonging, and depression among survivors of traumatic brain injury. J Nurs Scholarsh 2002, 34(3):221-226.

46. Baumeister $R$, Leary M: The need to belong: Desire for interpersonal attachments as a fundamental human motivation. Psychological Bulletin 1995, 117:497-529

47. Pinquart M, Silbereisen RK, Frohlich C: Life goals and purpose in life in cancer patients. Support Care Cancer 2009, 17(3):253-259.

48. Roberts KJ, Lepore SJ, Helgeson V: Social-cognitive correlates of adjustment to prostate cancer. Psychooncology 2006, 15(3):183-192.

49. Vickberg SM, Bovbjerg DH, DuHamel KN, Currie V, Redd WH: Intrusive thoughts and psychological distress among breast cancer survivors: global meaning as a possible protective factor. Behav Med 2000, 25(4):152-160. 
50. Taylor SE, Kemeny ME, Reed GM, Bower JE, Gruenwald TL: Psychological resources, positive illusions, and health. American Psychologist 2000, 55:99-109.

51. Schneider S, Moyer A, Knapp-Oliver S, Sohl S, Cannella D, Targhetta V: Preintervention distress moderates the efficacy of psychosocial treatment for cancer patients: a meta-analysis. J Behav Med 33(1):1-14

52. Moher D, Hopewell S, Schulz KF, Montori V, Gotzsche PC, Devereaux PJ, Elbourne D, Egger M, Altman DG: CONSORT 2010 explanation and elaboration: updated guidelines for reporting parallel group randomised trials. BMJ 2010, 340:C869.

53. Zigmond AS, Snaith RP: The hospital anxiety and depression scale. Acta Psychiatr Scand 1983, 67(6):361-370.

54. Carroll BT, Kathol RG, Noyes R, Wald TG, Clamon GH: Screening for depression and anxiety in cancer patients using the Hospital Anxiety and Depression Scale. Gen Hosp Psychiatry 1993, 15(2):69-74.

55. Trend data: Demographics of internet users. [http://www.pewinternet.org/ Static-Pages/Trend-Data/Whos-Online.aspx].

56. Kornblith AB, Powell M, Regan MM, Bennett S, Krasner C, Moy B, Younger J, Goodman A, Berkowitz R, Winer E: Long-term psychosocial adjustment of older vs younger survivors of breast and endometrial cancer. Psychooncology 2007, 16(10):895-903.

57. Jacobsen PB, Donovan KA, Trask PC, Fleishman SB, Zabora J, Baker F, Holland JC: Screening for psychologic distress in ambulatory cancer patients. Cancer 2005, 103(7):1494-1502.

58. Steger MF, Frazier P, Oishi S: The Meaning in Life Questionnaire: Assessing the presence of and search for meaning in life. Journal of Counseling Psychology 2006, 53:80-93.

59. Rosenberg M: Society and adolescent self-image. Princeton, NJ: Princeton University Press; 1965.

60. Watson D, Clark LA, Tellegen A: Development and validation of brief measures of positive and negative affect: the PANAS scales. J Pers Soc Psychol 1988, 54(6):1063-1070.

61. Rosenberg M, McCullough BC: Mattering: Inferred significance and mental health among adolescents. Research in Community and Mental Health 1981, 2:163-182.

62. Cutrona CE, Russell D: The provisions of social relatinships and adaptation to stress. In Advances in personal relationships. Edited by: Jones WH, Perlman D. Greenwich, CT: JAI Press; 1987:37-67.

63. Sangha O, Stucki G, Liang MH, Fossel AH, Katz JN: The Self-Administered Comorbidity Questionnaire: a new method to assess comorbidity for clinical and health services research. Arthritis Rheum 2003, 49(2):156-163.

64. Bambina A: Online social support: The interplay of social networks and computer-mediated communication. Youngstown, NY: Cambria Press 2007.

65. Lepore SJ, Helgeson VS, Eton DT, Schulz R: Improving quality of life in men with prostate cancer: A randomized controlled trial of group education interventions. Health Psychology 2003, 22:443-452.

66. Helgeson VS, Cohen S, Schulz R, Yasko J: Education and peer discussion group interventions and adjustment to breast cancer. Arch Gen Psychiatry 1999, 56(4):340-347.

67. Lepore SJ: A social-cognitive processing model of emotional adjustment to cancer. In Psychosocial interventions for cancer. Edited by: Baum A, Andersen B. Washington, D.C.: American Psychological Association; 2001:99-118

68. Ridner SH, Dietrich MS, Kidd N: Breast cancer treatment-related lymphedema self-care: Education, practices, symptoms, and quality of life. Support Care Cancer 2010.

69. Ganz PA: Quality of Life Across the Continuum of Breast Cancer Care. Breast J 2000, 6(5):324-330.

70. Stanton AL, Danoff-Burg S, Sworowski LA, Collins CA, Branstetter AD, Rodriguez-Hanley A, Kirk SB, Austenfeld JL: Randomized, controlled trial of written emotional expression and benefit finding in breast cancer patients. J Clin Oncol 2002, 20(20):4160-4168.

71. Davey A, Savla JS: Statistical power analysis with missing data: A structural equation modeling approach. NY: Rutledge; 2010.

72. Preacher KJ, Hayes AF: Asymptotic and resampling strategies for assessing and comparing indirect effects in multiple mediator models. Behav Res Methods 2008, 40(3):879-891.

73. Maxwell SE, Kelley K, Rausch JR: Sample size planning for statistical power and accuracy in parameter estimation. Annu Rev Psychol 2008, 59:537-563.

\section{Pre-publication history}

The pre-publication history for this paper can be accessed here: http://www.biomedcentral.com/1471-2407/11/379/prepub

doi:10.1186/1471-2407-11-379

Cite this article as: Lepore et al:: Standard versus prosocial online support groups for distressed breast cancer survivors: a randomized controlled trial. BMC Cancer 2011 11:379.

\section{Submit your next manuscript to BioMed Central and take full advantage of:}

- Convenient online submission

- Thorough peer review

- No space constraints or color figure charges

- Immediate publication on acceptance

- Inclusion in PubMed, CAS, Scopus and Google Scholar

- Research which is freely available for redistribution

Submit your manuscript at www.biomedcentral.com/submit
C) Biomed Central 